\title{
Defamiliarizing Heavy-Contact Sports: A Critical Examination of Rugby, Discipline, and Pleasure
}

\author{
Richard Pringle \\ University of Waikato
}

\begin{abstract}
Pleasure can be regarded as a productive force in the constitution of the social significance of sport and desiring sport subjects. The organization and use of sport pleasure has been a relatively marginalized topic of examination. To promote and examine sport pleasure, I conducted semistructured interviews with seven passionate rugby players. Transcripts were analyzed via Foucauldian theorizing and revealed the intertwined workings of technologies of dominance and self in the constitution of rugby pleasures. As a strategy to defamiliarize and disrupt habitual and uncritical acceptance of rugby aggression, I argued that rugby pleasures were akin to sadomasochism. Rugby can be understood as a taboo-breaking game associated with transparent relations of power connected with the pleasure induced from physical domination and the fear of pain.

Le plaisir peut étre vu en tant que force productive dans la constitution de l' importance sociale du sport et des sujets sportifs qui ddsirent. L'organisation et l'utilisation du plaisir en sport est un sujet d'etude relativement marginalise. Pour promouvoir et examiner le plaisir en sport, j'ai realise des entrevues semi-structurdes avec sept joueurs passionnes de rugby. Les transcriptions ont ete analysdes $\mathrm{h}$ la lumiere de theories foucaldiennes et ont revels le fonctionnement imbriqud des technologies de domination et du soi dans la constitution des plaisirs en rugby. Comme stratdgie pour ddfamiliariser et bouleverser l'acceptation habituelle et non critique de l'agression en rugby, j'ai suggerd Yid\& qu'au rugby, les plaisirs ressemblent au sadomasochisme. Le rugby peut titre compris comme un jeu qui brise les taboos et qui est associe $\mathrm{h}$ des relations de pouvoir transparentes rendes au plaisir venant de la domination physique et a la peur de la douleur.
\end{abstract}

The social significance of sport is well accepted among sport sociologists. Sport researchers no longer need to quote facts and figures to illustrate the social centrality of sport (Dunning, 1999) and Collins (2007) even suggested that it is "cliche to talk about the growing significance of sport" (p. 2). A related question of importance is why has sport become so significant? Although there are many possible answers to this question, Elias and Dunning (1986) theorized that at a

The author is with the Department of Sport and Leisure Studies. University of Waikato, Private Bag 3105, Hamilton, New Zealand. 
fundamental level sport is socially central as it allows people to engage in a quest for excitement that counters the routines and controls that shape life in civilized societies. Their argument, regardless of its veracity, positions the social construction of sporting pleasure as a phenomenon worthy of social examination.

In this article, I provide an empirical examination of the discursive constitution of rugby union pleasures to further promote the study of sport and pleasure. I focus on the male dominated, heavy-contact sport of rugby given its privileged sociocultural position within New Zealand. Rugby dominates the sports media, acts as a transnational medium for advertising, shapes understandings of gendered and national identities, and induces multiple emotional experiences, such as: fear, disgust, disappointment, anger, pride, pleasure, and excitement. I argue that closely linked to the production of these various emotions are experiences and observations of bodily risk and damage. Connell (1983), for example, asserted with respect to Australian Rules Football that: "A deft bit of passing, an accurate kick, is cheered by that side's supporters: but the jarring collision of two ruckmen at speed draws gasps and roars from the whole crowd" (p. 19). The emotional response to the "jarring collisions" not only produces spectator excitement but is also connected to the broader popularity and related social influence of heavy-contact sports. However, the fundamental place of embodied risk and pain can also make it difficult to understand what might be pleasurable about playing these sports. Feminist psychologist, Ritchie (1981), for example, declared:

I confess to being utterly unable to work out ... what the possible attraction can be in huddling in a scrum with one's head next to another player's buttocks or in lying in the fetal position at the bottom of a ruck while others rake you over with their boots. This is a game? (p. 139)

To gain insight into the seemingly incongruent mix of sporting pain and joy, I examine the social construction of rugby participation pleasures. I begin by presenting an overview of the sociological study of emotions and define how I understand the concept of pleasure. I then review how pleasure has been examined within sociological studies of rugby and develop the argument, more broadly, that the sociology of sport has tended to examine pleasure as an epiphenomenon and in subsidiary relation to various social issues. Next, I detail how I drew on Foucauldian theorizing to analyze, via in-depth interviews, the pleasures of seven rugby players from New Zealand. My discussion of results, to illustrate the integral link between mechanisms of power and the discursive construction of pleasure, focuses on the intertwined workings of technologies of dominance and self in the production of rugby pleasures. My subsequent analysis does not aim to romanticize rugby pleasures hut to reveal, in a critical manner, how these pleasures can be regarded as building blocks that prop up the social significance of the sport and its unintended discursive effects. I conclude by comparing rugby pleasures with sadomasochism $(\mathrm{S} \& \mathrm{M})$ as a strategy to defamiliarize the brutality of the sport. 


\section{The Sociology of Emotions and the Study of Pleasure}

The systematic study of the sociology of emotions began only three decades ago

(e.g., Bourdieu, 1980, 1986; Denzin, 1984; Featherstone, 1982: Hochschild, 1983) and has been associated with the broader "growth of interest in the cultural dimension of social life" (Featherstone, 1991. p. 133). Turner and Stets (2005) regarded this relatively late development as "remarkable in light of the fact that emotions pervade virtually every aspect of human experience and all social relations" (p. 1). Emotions, for example, are integral in processes associated with social interaction, social control, and with producing and challenging social structures, power relations and cultural traditions (Barthes, 1990; Bourdieu, 1986; Foucault, 1978, 1985). In recent years, major works on emotion have also appeared in political science, history, moral philosophy, economics, education studies and neuroscience (Berezin, 2002). Shilling (2002) further observed that, "emotional phenomena occupy an important place in sociology's heritage" ( p. 10)—such as the work of Comte, Durkheim, Weber, and Simmel-yet this rich heritage "has yet to be explicated fully by the sub-discipline" (p. 10).

The root word for emotions is "to move" and, in this manner, emotions can be thought of as productive forces rather than just reactive (Goleman, 1994). Huizinga (1970) in his classical but uncritical treatise on the play element in culture, as an example, contended that "culture arises in the form of play" (p. 23) and "pure play is one of the main bases of civilization" (p. 23). He romantically argued that it was through play that humans developed drama, dance, sporting contests, games of love and, at a much broader level, human culture. To explain the significance and constitutive abilities of play, Huizinga emphasized the importance of lived experiences of fun. Fun, in accordance with this logic, can be understood as the energizing force that is integral to the development of human culture. Other notable scholars have similarly contended that fun, or one of its synonyms, is a socially constitutive force. Freud provocatively argued that social life, although tempered by the reality principle, is governed by the pleasure principle or the drive to satisfy desires. Deleuze and Guattari (1984), in a related manner, theorized that desire is a productive force that constitutes the social.

Drawing from this line of argument, I contend that one of the man unintended outcomes of the human search for pleasure, or the productive result of desire, is the contemporary political, economic, and social significance of sport. Pleasure, more broadly, can be understood as a prime existential project, an organizing principle of social life, and a productive force in the constitution of desiring sport subjects. But what is pleasure and how can it be theorized?

Pleasure can be defined as a feeling or source of happiness, delight, or satisfaction. Although this simple definition has a collective currency, it is also circular. Indeed, pleasure, fun, happiness, and satisfaction are often used interchangeably in popular discourse and "even in academic literature" (Smith Maguire, 2008, p. 72). Smith Maguire (2008) contended, given the complexities associated with defining pleasure, that its significant characteristic is the "degree of instrumentality: is the leisure form pursued as an end in itself or is it pursued as a means to some other end?" (p. 72). Shilling (2002), however, asserted that it is not "useful or even possible to provide a precise definition of emotions" (p. 12). 
In following Shilling, I do not attempt to provide a tight definition but use the term pleasure in a broad, inclusive, positive-affect sense. An advantage of using this definition with loose boundaries is that wider aspects of the phenomena, that might be beneficial for understanding complex social processes, are not eliminated from study (Izard, Kagan, \& Zajonc, 1984). More specifically, I adopt a social constructionist view of emotions as shaped by Foucauldian theorizing. In drawing from Foucault $(1977,1985)$, I am skeptical of the idea that pleasure is the simple product of biological, psychological, or personal appetites. I accept that human experiences of pleasure are constituted, negotiated, and organized through available discourses and are simultaneously the product of certain forms of training or disciplining. ${ }^{1}$ Different systems of thought and mechanisms of power in different epistemes, therefore, shape how humans experience, understand, manage, and use pleasure. Pleasure, in this manner, can be understood as a multifaceted, complex, subjective, and, at times, seemingly contradictory emotional experience. Pleasure can be experienced, for example, in playing sport in pain, doing unpleas ant exercises, or, somewhat ironically, in resisting pleasure (such as via dieting).

Given that sports center on embodied actions and the pursuit of excitement, Maguire (1992) noted that it is strange the emotions have not received greater attention from sport sociologists. In the following section, I draw on sociological examinations of rugby to illustrate that examinations of lived experiences of pleasure are relatively rare.

\section{Rugby and the Marginalization of Pleasure}

The linkages between sport and pleasure have been explicated via several theoretical perspectives including: figurational sociology (Elias \& Dunning, 1986), post-structuralism (Fiske, 1991), edge theory (Lyng, 1990, 2005), Deleuzean theorizing (Pronger, 1999), postmodernism (Stranger, 1999), affect theory (Booth, 2008; Evers, 2006) and via the psychological construct of flow (Csikszentmihalyi, 1997). Empirical analyses that focus specifically on lived experiences of sporting pleasures are, however, comparatively rare within sociology. Maguire (1992) simply asserted, "We are dealing here with a relatively unexplored landscape" (p. 118). Of the limited number of studies that have overtly examined sport pleasure, there has been a tendency to explore pleasure as related to excitement and thrill, and as associated with seemingly dangerous or deviant activities (e.g., Celsi, Rose, \& Leigh, 1993; Duncan \& Brummett, 1989; Finn, 1994; Stranger, 1999). The studies that have examined pleasure in so-called extreme sports are typically underpinned by a desire to understand why a growing number of individuals purposefully seek risk and how the postmodern condition relates to this growth (e.g., Celsi et al., 1993; Le Breton, 2000; Moller, 2007; Stranger, 1999). Despite the increased academic interest in extreme sports, risk and thrill (e.g., Booth \& Thorpe, 2007; McNamee, 2007; Olivier, 2006; Sydnor \& Rinehart, 2003), a broader examination of lived pleasures in "mainstream" sport remains somewhat marginal. Moreover, when sporting pleasures are examined, they are typically examined in subordinate relation to various social issues. The following review of research concerned with the high-speed collision sport of rugby illustrates this point. 
Sociological examinations of rugby have typically drawn on critical theory and primarily focused on rugby's links to inequitable relations of power in accordance with the production of identities that are gendered (e.g., Chase, 2006; Dunning, 1986; Nauright \& Chandler, 1996; Pringle \& Markula. 2005; White \& Vagi, 1990), sexualized ( Price \& Parker, 2003; Wheatley, 1994; Wright \& Clarke, 1999), racialized (e.g., Falcons, 2007; Grainger, 2006; Jackson \& Hokowhitu, 2002; MacLean. 1999), violent or injured (e.g., Schacht, 1996: Sparkes \& Smith, 2002) and nationalized (e.g., Andrews \& Howell, 1993; Fougere, 1989; MacLean, 2003; Tuck, 2003). The social processes involved in the shaping of these diverse rugby subjectivities and associated relations of power are acknowledged as complex and dynamic (Donnelly \& Young, 1985), yet the subsequent representation of rugby tends to emphasize its articulations with social problems and injustices. Rugby masculinities, for example, are primarily illustrated as tied to displays of strength, pain tolerance, aggression, and crude taboo breaking practices that act to reaffirm a problematic form of masculinity and inferiorize females and "alternative" masculinities (e.g., Donnelly \& Young, 1985; Nauright \& Chandler, 1996; Schacht, 1996; Sparkes \& Smith, 2002).

Despite the prime focus on social problems, these critical examinations also reveal rugby as a site for the construction of multiple pleasures. Studies, for example, have revealed how rugby can produce pleasure via: bruising physicality and involvement in a mock battle (Chase, 2006; Elias \& Dunning, 1986; Sheard \& Dunning, 1973; Young \& White, 1995); inducement of friendships and team work (Carle \& Nauright, 1999); development and display of skill, fitness and strategy (Chu, Leberman, Howe, \& Bachor, 2003; Light, 2007); physical contact and intimacy (White \& Vagi, 1990; Gard \& Meyenn, 2000); affirming and/or challenging gendered identities (Chase, 2006; Donnelly \& Young, 1985; Dunning, 1986; Price \& Parker, 2003; Pringle \& Markula, 2005; Wheatley, 1994) and televisual voyeurism (Star, 1992). These rugby pleasures span a broad array yet are typically cited in secondary relation to a social issue. These various pleasures, accordingly, are not analyzed in-depth as the issue of prime concern relates to the social problem. Sociological examinations of sporting issues and injustices dominate and override analysis of sporting pleasure under the prominence of a critical gaze.

The apparent marginalization of lived experiences of rugby pleasure suggests that critical researchers do not value this topic or that other topics are of greater importance to examine. Barcan (2002) reflected on her theoretical journey and offered an explanation as to why critical examinations of pleasure are rare:

I have experienced critical theory as a practice marked by its suspicion of hope or joy, perhaps because they are seen as religious values. I have also found a tacit equation of optimism with both intellectual inferiority and political betrayal. If you are optimistic or joyful about the world, it's because you're not bright enough to realize how corrupt it is, or not politically committed enough to jolt yourself out of your bourgeois comforts. (p. 345)

Barcan (2002) argued that critical examinations of pleasure are uncommon as such a focus might indirectly suggest that the researcher is politically naive. Yet, 
if we accept Huizinga's (1970) and Deleuze and Guattari's (1984) respective arguments that play and desire are productive forces in the constitution of human societies, it can be reciprocally argued that it would be naïve to marginalize the sociological examination of pleasure: as desire or the search for pleasure can be understood as central to the production of social inequities. The objectification and sexualization of bodies in the sport media, as an example, appears closely linked to the economy of (male heterosexual) desire and the subsequent production of inequitable relations of power between males and females. In this manner, the politics of pleasure can be understood as having very real social and material consequences (Tiger, 1992). Maguire et al., (2002), accordingly, suggested that the sociological study of sporting emotions should examine how "embodied acts both reflect and reinforce social inequalities, be they class-, gender-, ethnicity- or disability based" (p. 184). Sporting pleasure, as such, demands critical analysis and a small number of researchers have taken up this challenge within sociological examinations of rugby.

Gard and Meyenn's (2000) examination, as an example, of how boys negotiate experiences of sporting pain and pleasure was inspired by the observation that heavy-contact sports provide a unique context within which intimate physical contact and acts of violence are legitimated for Western males. They were intrigued by the contention "that for many heterosexual-identifying men the desire for friendly or intimate physical contact needs to be camouflaged behind a display of physical violence" (p. 28). Their results revealed that the interviewees enjoyed the robust physicality of contact sports yet the issue of whether this enjoyment was related to a longing for close physical contact with other males was not sufficiently explored.

MacLean's (2003) postcolonial analysis, in contrast, provided a detailed excavation of the links between fandom, pleasure, and politics to understand the massive civil protests associated with the apartheid related 1981 South African rugby tour of New Zealand. He argued that New Zealand rugby fans, via the development of affective dispositions, linked the pleasures and meanings of rugby with nationalist discourses so that the protests - that aimed to halt the "racist tour"-were viewed as a threat to a way of life. MacLean cogently illustrated the importance of examining the social development of affective economies to understand political and social issues associated with sport.

The work of Gard and Meyenn (2000) and MacLean (2003) illustrate how rugby pleasures are linked to sporting injuries, construction of gendered and nationalistic identities, and issues associated with social control and change. Despite the acknowledgment of the social significance of sporting pleasures, little is known about the interplay of social processes that result in the construction of rugby players' understandings of pleasure. This recognition provided the impetus for this current study. I speculated that a broader understanding of the social construction of rugby pleasures could provide insight into the production of rugby cultures, identities, values, and associated social issues. 


\section{Notes on Method: A Foucauldian Take on Examining Experiences of Pleasure}

I examined how rugby players make sense of their broad experiences of pleasure by conducting in-depth interviews with seven New Zealand men. The interviews were conducted as part of a larger study that examined the discursive connections between masculinities and rugby experiences of fear, pain, and pleasure (Pringle. 2003 Pringle \& Markula. 2005). The pseudonyms used in this previous research have been maintained. The interviews varied in length between two and five hours, were recorded via audiotape, and transcribed verbatim. The seven men ranged in age from 21 to 50 years; three identified as Maori and four as Pakeha or of European descent. Only one of the interviewees had played professionally. Given the age differences of the interviewees it should be clear that they were reflecting on rugby experiences that spanned different time periods (1970s to 2000s) and contexts. The interviewees were selected through purposeful sampling techniques in relation to adult men who identified they had been or were still passionate rugby players. Within the interviews, these men were invited to talk about their introduction to rugby culture, accounts of practice sessions and games, and highlight their affective relations with rugby. The interviewees were asked specifically to detail and attempt to explain their experiences of pleasure within the broad context of rugby.

I analyzed the transcripts in relation to Foucault's (1978, 1985, 1986) framework for examining sexuality and experiences. Foucault (1978) analyzed the social forces that produce desiring subjects in his first genealogical volume of sexuality. His somewhat radical aim was to illustrate how the workings of power and circulation of discourses shape desire and change patterns of sexuality over time. Foucault's prime conceptual tools, as related to identifying the workings of discourse and power, have received significant attention from sport sociologists and need little introduction here. ${ }^{2}$ In writing the history of sexuality, Foucault (1978) aimed

to locate the forms of power, the channels it takes, and the discourses it permeates in order to reach the most tenuous and individual modes of behavior, the paths that give it access to the rare or scarcely perceivable forms of desire, how it penetrates and controls everyday pleasure. (p. 11)

Foucault was interested in excavating social processes that individuals have little control over but nevertheless shape sexual desires and actions. In drawing from Foucault, I was firstly interested in examining the workings of discourse and power to understand the constitution of individuals with desire to play rugby. I aimed to identify the discourses that encouraged or demanded participation in rugby and the technologies of dominance that controlled bodies, aptitudes, and desires during training sessions and games. I was also guided by Foucault's $(1985,1986.1988 \mathrm{a})$ later work on sexuality, within which he directed less attention to techniques of domination and focused on how individuals' negotiate experiences of pleasure. As a strategy to analyze experiences, Foucault (1997a) suggested a three-pronged approach: 
... it means trying to decipher how ... a complex experience is constituted from and around certain forms of behavior: an experience that conjoins a field of knowledge [connaissance] (with its own concepts, theories, diverse disciplines), a collection of rules (which differentiate the permissible from the forbidden, natural from monstrous, normal from pathological . . .), and a mode of relation between the individual and himself (sic) (which enables him to recognize himself as a sexual subject amid others). (p. 200)

Drawing from Foucault, I was interested in understanding how the interviewees negotiated their experiences of rugby pleasure in relation to the field of knowledge or discourses that surrounded rugby, the written and unwritten rules that constitute and prohibit particular rugby actions, and the webs of social relations that the interviewees were enmeshed within, including an interviewee's relation with himself. Overall, I examined how the workings of discourse and power or technologies of dominance constituted "subjects" who desired to play rugby but also how these subjects negotiated experiences of pleasure. In undertaking the analysis, I assumed that technologies of dominance and of self operated simultaneously.

More generally, I was inspired by Foucault's (1988b) critical stance toward knowledge construction, within which he characterized his epistemological goal as attempting "to disturb people's mental habits, the way they do and think things, to dissipate what is familiar and accepted, to re-examine rules and institutions on the basis of this reproblematization" (p. 265). My political intention, accordingly, was not to simply reveal the social construction of rugby pleasures but to problematize them by making the familiar strange.

\section{Making Pleasures Strange: Discussion of Results}

I present the results in five sections. Firstly, I discuss the interviewees' accounts of their rugby pleasures in relation to Foucault's ideas on the workings of discourse and disciplinary technologies. I then examine the importance of the context of pain for understanding the construction of rugby pleasures. This is followed by a discussion of whether the rugby players' subjective experiences of pleasure can be satisfactorily explained. In accepting that it is difficult to provide a definitive theoretical account of rugby pleasure, I then adopt a critical strategy of defamiliarization by drawing comparisons between rugby and S\&M. Lastly, I argue that $S \& M$ can be used as heuristic device for critically understanding the broader culture of rugby.

\section{Technologies of Dominance and the Production of Desiring Rugby Subjects}

Foucault (1980) stated that a form of power he was interested in examining throughout the 1970s was one that produces "discourses of truth" (p. 94) with associated potent effects; the effects he was concerned about referred to the judgment, normalization, classification and control of subjects so that they were "destined to a certain mode of living or dying" (p. 94). The interviewees' accounts of their boyhood inductions into competitive rugby revealed that the discourses of 
rugby had such potent effects. They discursively knew of the sport as an exciting but rugged game ideal for male, and male only, participation. More generally, rugby was spoken into existence by the interviewees as New Zealand's national sport and as the most important sport in their schools. These discourses of rugby coalesced in a symphony of accord to compel the interviewees to play rugby at a young age. These discourses, more specifically, produced their understanding that it was normal for boys to play and simultaneously abnormal not to. Previous research has illustrated how this process of normalization acts as dividing practice to constitute some boys' bodies as deviant and how this leads to processes of social and physical marginalization (Prin ${ }^{\mathrm{g}}$ le \& Markula, 2005). Yet the processes of normalization, for those who participated in rugby, were also linked to the reciprocal production of social acceptance and associated experiences of pleasure. Tom as an example, reflected on how participation provided an avenue for social acceptance that subsequently induced pleasure:

Well, rugby was really my saving; it gave me something to be proud of.... In my senior class at primary school I wasn't really accepted in the "cool" group in our year . . . and intellectually I was just average. But my saving grace at school and with my headmaster was that I was a very good rugby player and so I would get respect by performing in the sport arena. And so I just loved, totally loved, rugby.

In a similar manner, Colin, who eventually played professional rugby, revealed that as a boy he felt different and rugby was attractive as it offered a possible means to feel normal:

I was quite a fat kid, and I didn't like being singled out, but on the same token, I was very social and liked having friends.... I was playing rugby, you know, as I was trying to fit into that group of kids. I didn't want to be a superstar or anything like that, all I wanted to do was be like the other kids, the other little group that we used to hang around with, I wanted to be like them.

The normalization of athletes should not necessarily be regarded as a passive process within which athletes are discursively coerced. In contrast, it was apparent that several of the interviewees actively reflected on the dominating discourses of rugby and opted to participate, in part, to gain a secure sense of self and the pleasure associated with being "normal." The seven interviewees subsequently allowed rugby to dominate their weekly winter schedules for many years to come. This was notwithstanding their recognition that the risk of sustaining serious injury and even permanent bodily damage was real: all seven, for example, eventually required medical treatment for a range of injuries including concussions, dislocations, sprains and broken bones, and four required surgical treatment and endured periods of hospitalization.

Despite concern about bodily well-being, all of the interviewees accepted that they were required to risk injury in the pursuit of victory. The rugby players, like soldiers in war, performed in a docile and disciplined manner. Shogan (1999) reported that athletes have typically been subject to the rigors of extensive training regimes to help achieve this seemingly ambiguous blend of traits. Disciplinary regimes, according to Foucault (1977) increase the force or productivity of the 
body but at the same time produce a politically obedient body: "Thus discipline produces subjected and practised bodies, 'docile' bodies" (p. 138). Indeed, it takes considerable disciplining, over an extended period, to induce a player's desire to lie on the ground to protect the ball while others stomp or ruck his/her body with sprigged boots.

The interviewees could all remember, sometimes in exquisite detail, the embodied requirements of their rugby training regimes. They talked of challenging and grueling training sessions that increased in intensity as they aged from their youth. In a similar manner, Foucault (1977) described the ways in which discipline proceeds with respect to exercise: "Exercise is that technique by which one imposes on the body tasks that are both repetitive and different, but always graduated . . . and which would involve from year to year, month to month, exercise of increasing complexity..." (p. 161). The training sessions at the adult level were clearly intense and the interviewees had mixed reactions. Willy bluntly stated, "I hated the training. It was just hard work and you knew your body was going to get thrashed. I got pushed to the end, and I didn't really know how to handle that." Morris was also concerned by the intensity of the training sessions: "I can remember getting so fatigued in some of the fitness sessions that my lungs felt like they were going to burst, and my muscles turned to jelly." Yet, Morris was not resentful about being pushed to his limits. In fact, he learned to appreciate the workouts and was soon augmenting these practices with his own fitness regimen: "One of the long lasting benefits of rugby was that I developed my love of running. . . . For added fitness I would run in the hills at the back of my school and that love has stayed with me till today."

Foucault (1977) detailed how "discipline proceeds from the distribution of individuals in space" (p. 141) and how it employed technologies related to enclosure (e.g., rugby team drills within bounded areas), partitioning (e.g., team positions), function (e.g., the specific role of each position), and rank (e.g., coach, captain, forward leader, reserve). Overall, the rugby training regimes can be regarded as disciplinary projects to help produce rugby bodies with select "movements, gestures, attitudes, rapidity" (Foucault, 1977, p. 137) and "individually characterized, but collectively useful aptitudes" (p. 162). The most useful aptitudes were toughness and competitiveness. A productive body in rugby is skilled and hardened; yet such a body is only useful if it desires to seek victory in the face of pain. The disciplinary techniques employed in training rugby players, accordingly, aimed to produce well-drilled, fit, tough, competitive players to enhance the chances of victory on Saturdays.

Foucault (1977) wrote about disciplinary technologies, as he was concerned that this form of power had pervaded modernity and worked in an insidious manner to control and shape subjectivities and social life. His aim, therefore, was to raise critical awareness about how these technologies could adversely affect people. As an antiessentialist, he accepted that disciplinary technologies were not inherently good or bad. In this manner, his target of concern was not the disciplinary techniques per se, but their power effect. Sport sociologists who have drawn on Foucault's ideas of disciplinary technologies have similarly aimed to raise critical awareness about how these techniques are employed in sport or exercise settings to produce certain bodies and encourage individuals into a "discursive web of normalising practices" (Markula, 2003, p. 88). Rugby players, for exam- 
ple, are disciplined to accept pain and injury as somewhat normal (Pringle \& Markula, 2005). The power effect of disciplinary technologies within sport and exercise settings, have been typically represented as oppressively controlling (see Gruneau, 1993).

The interviewees revealed, however, that the technologies of dominance employed in rugby were also linked to the production of various forms of pleasure. Morris, for example, enjoyed the pleasure linked to disciplinary systems of rank employed within his secondary school: "After playing four games for the First XV we got to wear a blue blazer which marks you out and very much puts you at the top of the status system." As a more sport specific example, Willy revealed how the grueling training sessions were related to moments of pleasure on the field of play:

It's magic when the team clicks and it just happens ... when the ball pops out of the scrum and is flicked down the backbite in a move that you've practiced and that gap opens up. Or, you know, when you are backing up someone who has made a break and in a split second, before you've had time to think, you cut inside, the ball pops up right in front of you, and the whole thing rolls on in a blur with other players backing up.... You live for those moments.

Willy's account illustrated how the well-disciplined team can function machine-like in an unthinking blur of automation to produce "magic" and, importantly, how these "moments" sustain and constitute a desire to play rugby. These moments of "flow," as Csikszentmihalyi (1997) would call them, are intimately related to disciplinary technologies. Deleuze and Guattari (1984) even argued that human assemblages as "desiring-machines" represent "the fundamental category of the economy of desire" (p. 32). Another example to illustrate how rugby pleasure is linked to disciplinary technologies relates to Darryl's initial concern with tackling:

Before my First XV I had never been taught how to tackle properly, you know, where to put your head and shoulders, how to keep your back straight. And I had been knocked out twice while playing as a schoolboy and both of them were in the tackle. But after being taught how to tackle, with lots of drills on the tackle bag, I felt much safer and more confident....Since then I've always loved tackling. I think it's the physical challenge that I enjoyed.

In Darryl's account, the disciplining processes associated with mastering the tackle, perhaps the most dangerous and anxiety producing aspect of rugby, encouraged a degree of confidence and ability that also produced pleasure. This pleasure, however, was not the simple product of disciplinary technologies but was also framed by Darryl's discursive understanding of rugby as a "noble game" for New Zealand males. More broadly, the union of discourses surrounding rugby in combination with the related disciplining processes constituted the interviewees' rugby pleasures as personally meaningful. And these meanings were significant in fueling rugby desire. According to renowned holocaust survivor and logotherapist, Viktor Frankl (1992), the search for meaning in life is a primary motivational force: 
There is nothing in the world, I venture to say, that would so effectively help one to survive even the most worst conditions as the knowledge that there is a meaning in one's life. There is much wisdom in the words of Nietzsche: "He who has a why to live for can bear almost any how." (p. 109)

Individual experiences, interpretations, and meanings of pleasure can be regarded as shaped by the interconnected workings of discourse and power and, more broadly, public policy (e.g., educational practices) and systems of governance. Rojek (1985) similarly suggested that: "leisure experience is not an essence in human societies, but an effect of systems of legitimation" (p. 178). The distribution of sporting pleasures is, accordingly, subject to inequities associated with the workings of power. For example, it is typically (but not exclusively) able-bodied, confident, and well-disciplined males who have the possibility to gain meaningful pleasures in rugby. Yet it is typically only this select group who also sustain the financial and emotional cost of rugby injuries.

Although the workings of discourse and power shape who participates in sport-and technologies of dominance subsequently work to control bodily performances, aptitudes and aesthetic experiences within sporting contexts - the interviewees revealed that they continuously negotiated their relationships with rugby. In this manner, they had degrees of "freedom" and were not totally controlled by the technologies of dominance. Foucault (1987) did not view power and freedom as mutually exclusive but accepted that freedom was a precondition for a relationship of power: within a relation of power "there is necessarily the possibility of resistance for if there were no possibility of resistance, of escape, of ruse, of strategies that reverse the situation-there would be no relations of power" (p. 12). Rugby players can, for example, "practice freedom" by being unavailable for play, missing practices, not executing game plans, feigning injury, retiring or, in the extreme, rejecting the sport (as Morris, with mixed emotions, eventually did).

The interviewees' accounts of their adult rugby experiences revealed that they only continued to participate because they expected to gain from it. More specifically, they primarily negotiated their participation in rugby in relation to the pleasure gained and the fear or reality of injuries. These negotiations were not undertaken in a cold and calculating manner, but were colored by affect in relation to the field of knowledge surrounding rugby. Although numerous studies have previously illustrated athlete's interpretations of pain and injury, few have revealed their understandings of sporting pleasure. So what were these rugby pleasures and how did the players rationalize them?

\section{Negotiating Rugby Pleasures Within the Context of Pain}

The interviewees expressed passion about playing rugby yet some found it difficult to verbalize fluently their pleasure. "It's sometimes hard to know," Torn reported, "why you are passionate about something." Angus similarly confessed that he "hadn't thought about this before" but knew that rugby participation produced a "high" This difficulty in explaining rugby pleasure reveals that the crisis of representation (Denzin \& Lincoln, 2005) is not just an academic issue but is entrenched in the complexities of understanding embodied and emotional experi- 
ences. Despite difficulties in verbalizing rugby pleasures the interviewees' highlighted several aspects related to their general enjoyment. These reasons-which were not unique to rugby and could have been gained in less damaging sports-included: the joy of participating in a sport that required strength, fitness and speed; the development and successful execution of physical skills; the team environment and social connectedness; the physicality and competitiveness of the game; and the pleasure of devising and implementing strategies and tactics. These explanations were similar to those offered by female rugby players (e.g., Carle \& Nauright, 1999; Chase, 2006; Chu. Leberman, Howe, \& Bachor, 2003: Young \& White, 1995; Wheatley, 1994) and intimate that discourses of gender, although important, should not be overemphasized in the examination of sporting pleasures after athletes have become committed participants (see Curry, 1993).

To help examine whether rugby provided relatively unique experiences of pleasures, I asked the interviewees to compare rugby with its popular summer counterpart "touch rugby": a modified version that eliminates the heavy contact such as tackling and scrummaging. Despite the similarity of this sport, many reported that without the hard physicality of rugby, touch rugby lacked intensity and was not so pleasurable. Tom stated, "I don't have a lot of time for touch.... I really missed the tackling side of rugby and it annoys me to jig around and someone touches you and it's all over ... just sort of spoils the game." Willie further explained that although he enjoyed "being able to get through the gaps" in touch rugby, that tackle rugby was more thrilling to play "because of the excitement of hitting somebody or tackling somebody." When 1 asked Willie to elaborate on what was exciting about hitting or tackling, he advised with a spirited look in his eyes: "Just knowing that I ... stopped my opposite number ... hit them in the tackle, made them knock the ball. Or I ran over the top of them (or) you just smash into them." For Willie, it was apparent that the ability to physically dominate and possibly hurt an opponent produced a specific thrill. In a more overt manner, Kahu uniquely confessed that when he first returned to rugby as a 21 -year-old, after a stint in prison, his sole objective was

to try and hurt some big guy. Or if some guy's got a reputation, I'd try and go out and hurt that person before he hurts you. And I spent most of my time either in the sin-bin or going and having a shower (being sent off) in the first half.

Some of the interviewees, however, disapproved of overt violence in rugby. Darryl was "critical of the stupidity that leads to . . thuggery and of people who use the game as an inappropriate outlet for their problems or their violent nature." And Colin was thankful that "the game is changing. Like you get sent off-three send offs or three sin bins - and you're out ... it's not the hard grind it used to be." Nevertheless, the interviewees were clear that the competitive physically confrontational nature of rugby, with its associated embodied risks, was closely related to what made the game uniquely exciting, anxiety producing and intense.

Before a tackle union game, I would have intense anxiety. You know I would have butterflies. I would have to go to the bathroom. And there was something quite... exciting or a high, almost a high in a way of shifting from that anxiety into comfort once the game starts... as soon as I either tackled someone 
or someone tackled me, the anxiety was gone... The anxiety was about fear of getting hurt I think. And so . . . once it starts, that fear would sort of go away and a high would replace it. (Angus)

The fear of being hurt and/or the ability to physically dominate another player provided the relatively unique context within which the interviewees could gain rugby pleasures. Rugby participation did not produce the same intensity of passion without this context of fear and pain. This relatively unique form of pleasure appeared fundamental to the production of desire to play. Colin, as an example, somewhat dramatically confessed:

The view in my mind is that each Saturday I go to war, and that's the way I look at it. And ... talking to myself like that makes me focus and zero's me in because ... there's that intensity. . . I'm not the only one, there's a group of us now that liken it to going to war. ... It's about being physically able to push yourself to the limits but mentally going that next step.

For Colin, the idea of going to war each Saturday was exhilarating and this pleasure constituted his subjectivity and rugby desire. Indeed, the interviewees revealed that the embodied risks and confrontational thrills of rugby took players to an intoxicating and spine-tingling edge. For some, the thrill of rugby was addictive. Colin, for example, reported suffering withdrawal symptoms after he was forced from the field of play for 18 months due to a neck injury: "I don't know whether you call it depression or whatever but I had a very, very low time, you know, like drinking constantly and firing up on the piss, which is not like me."

The risk of pain on the field not only made the game more intense but also promoted a greater sense of social connectedness. Working as a team meant more than simply playing to win, as the possibility of serious injury encouraged players to "look out for each other" (Colin). This risk-related experience of care enhanced some of the interviewees' sense of community or "sensual" solidarity and this bond extended beyond the field of play. In this manner, the peculiar mix of risk, pain, social connectedness, and excitement appear important in the constitution of subjects with a desire to play rugby. Yet can a more definitive explanation of rugby pleasures be offered?

\section{Can Subjective Experiences of Pleasure be Satisfactorily Explained?}

Elias and Dunning (1986) suggested that sport "violence in the form of 'play fight' or 'mock battle' between two individuals or groups is a central and legitimate ingredient ... for the socially acceptable, ritualized and more or less controlled expression of physical violence" (p. 81). To help explain the pleasurable excitement of participating in a mock battle, Elias (1986) argued that such battles have a "strong propensity for stirring up emotions" (p. 49) but that it is a "well-tempered excitement without the risks and tensions usually connected with excitement in other life-situations, a 'mimetic' excitement" (pp. 48-49). This mimetic excitement, moreover, is produced with a "minimum of injuries to human beings" (p. 59). Yet the interviewees' rugby stories do not fully resonate with this argu- 
ment. In fact, participation produced severe damage, not a minimum of injuries, to their competitive rugby bodies. Cohn suffered five concussions on the rugby field, five broken bones (thumb, cervical vertebrae, spiral fracture of ulna and two nose breaks) and had undergone numerous operations: "... two on my ankle, two on my knee, this ear rebuilt, I've had my nose straightened once but it's been broken again since I've had that done." Rugby pleasure, accordingly, does not appear well tempered or mimetic.

In contrast, the interviewees' accounts of rugby pleasures as related to the intense mix of joy and pain/excitement and anxiety resonate a little more closely with Stranger's (1999) thesis concerning the aestheticization of surfing. Adopting Stranger's postmodern argument, one could argue that sublime rugby feelin ${ }^{\mathrm{g}} \mathrm{s}$ of pleasure and pain induce players to blur the romantic image of rugby with its brutal reality in a way that distorts their interpretation of risk and perpetuates their desire to play. Yet, as perhaps different from surfing, it would be disingenuous to suggest that rugby players participate with a romanticized understanding of bodily risk or that they ignore the risk of pain. The interviewees, for example, revealed that they were acutely aware of the possibilities and realities of severe bodily damage in playing rugby. More importantly, this knowledge id risk and pain amplified the intensity and excitement in participating. In contrast, pleasure was reduced or lost when the risk of serious pain and injury was removed, such as in touch rugby.

Attempting to satisfactorily explain or account for pleasure is a complex task. Huizinga (1970) even declared that the fun element of play, the element that makes play desirable, "resists all analysis, all logical interpretation" t p. 21). Similarly, the significance of the sublime for Lyotard (1994) was that it indicated an aporia or limit to human reason, which concomitantly illustrated the insecurity, multiplicity and constant change evident in the postmodern world. In recognition of these difficulties, I do not attempt to provide a definitive clarification of the multiple pleasures of rugby. In contrast, I draw comparisons between rugby pleasures with Foucault's (1997b) ideas on S\&M, as a less ambitious strategy for understanding the complex pleasure/pain mix in rugby. In arguing that the heavy-contact pleasures in rugby are tangentially analogous to S\&M practices, I aim to problematize rugby culture - a sport that is uncritically celebrated within New Zealand. In following Foucault (1988b), I aim to "disturb people's mental habits" (p. 265) by making the familiarity about rugby strange. In doing this, I reveal my biases: I admit that I find the concept of S\&M bizarre and-although I was once a passionate rugby player-I now find the damaging and bruising pleasures of rugby bizarre.

The strategy of defamiliarization developed within literary theory and is typically attributed to the work of Russian formalist Victor Shklovsky, before being adopted by semioticians and anthropologists (Bell, Blythe, \& Sengers. 2005; Kaomea, 2003). It is based on the assumption that as we become familiar with objects or ideas, we take them for granted and this familarization process limits our critical perceptions. Literary devices, such as rhyme and metaphor, can work to defamiliarize everyday language and encourage readers "to grapple with language in a more strenuous, self-conscious way than usual" so that "the world, which that language contains, is vividly renewed (and) our habitual responses are refreshed and familiar texts are rendered more perceptible" (Kaomea, 2003, p. 
15). Within sport sociology, Messner (1990) used the strategy of defamiliarization by metaphorically suggesting that sporting bodies are, at times, weapons. With similar intent, I draw comparison between S\&M and rugby pleasures, via use of simile, to defamiliarize and stimulate critical reflection.

\section{Rugby Pleasures as Sadomasochism: A Strategy of Defamiliarization}

S\&M is defined as the gaining of pleasure, typically but not exclusively in regard to sexual practices, by alternately or simultaneously enduring and causing pain to somebody else. The talk of the interviewees in gaining pleasure from dominating others in rugby, excitement in going to war and of the shift from anxiety to a "high" with respect to the fear of pain resembles the realm of a desexualized S\&M. Bale (2006) has similarly illustrated how runners gain a form of pleasure comparable to S\&M via the enjoyment of suffering, through pushing the body to its limits, and in inflicting pain via the pleasure of "beating" others or aiming "to 'burn off' their opponents ... (and) 'run them into the ground"' (p. 69). Yet the case of rugby appears more closely aligned to $S \& M$ than running. To help make this comparison, I draw on Foucault's ideas about S\&M.

Foucault (1997b) rejected that S\&M practices are related to unconscious desires. In an unusually blunt manner he stated, "The idea that S\&M is related to a deep violence, that $S \& M$ practice is a way of liberating this violence, this aggression, is stupid" (p. 165). In similar manner, the interviewees suggested the idea that they participated in rugby to liberate innate tendencies for aggression or violence was farcical. In fact, all of the interviewees denied that they were violent, even when discussing their participation in actions of unequivocal violence. Colin, as an example, reported he had punched and broken an opponent's nose to teach him a lesson: "I don't gain satisfaction from that shit, but at the same time I've sort of become accustomed to it and I don't mind doing it ... (but) I mean it makes me sound like a thug and I don't think I am." Moreover, nearly all of the interviewees rationalized that rugby was simply a game and, as such, was not violent. Nevertheless, they all accepted that the context of embodied risk, as associated with the ability to inflict and absorb pain, made participation exciting.

Foucault's (1997b) apparent interest in S\&M was not characterized by fascination with violence, cruelty, or harm but with creative participation in games of power. He reported that the workings of power in S\&M are different from how power is typically exercised, as it is transparent:

The S\&M game is very interesting because it is a strategic relation, but it is always fluid. Of course, there are roles, but everybody knows very well that those roles can be reversed. Sometimes the scene begins with the master and slave, and at the end, the slave has become the master. Or, even when the roles are stabilized, you know very well that it is always a game. Either the rules are transgressed, or there is an agreement, either explicit or tacit, that makes them aware of certain boundaries. (p. 169)

The roles associated with dominating or being dominated are also fluid within rugby, because the tackler and oppositional ball carrier change roles throughout 
the game and both can end up being punished dependent on the success of their performances: The uncertainty of punishment Contributes to the context of pleasure. Moreover, participants consent to being tackled or rucked and possibly even being punched, but the line is drawn with pain inflicting techniques such as eye gouging or ear biting. In this manner, rugby involves a perverse mix of institutionalized and unwritten rules concerned with the legitimacy of techniques of violence, as evidenced in the following interview excerpt with Morris (who played during the 1980s):

Morris: I would imagine that in an average rugby game I would have been punched or kicked, I don't know, difficult to put a number on it, but frequently. There wouldn't be a game where I hadn't been kicked or punched and...

Richard: Where did you get kicked?

Morris: Oh, in the bottom of rucks or whatever, you know, a lot of tackles. And in most games, I would have done the same thing back. I think there was a kind of acceptance, a kind of an unwritten rule that kicking somebody in the head was kind of marked or moved from acceptable violence to non-acceptable violence. . . The violence was just very much part of the game and seen as good vigorous play and especially if somebody had pulled a jersey or had put you in a headlock in a tackle or whatever, I would feel that needed to retaliate otherwise I would he, you know, would be deemed dominated ... I needed to assert authority I suppose in the game. So I have very clear memories of rugby as being violent.... I think there was a place where some people would he seen as a dirty player, that was kind of frowned upon at some levels but that would be where somebody was seen as initiating the unacceptable violence ...

Richard: The kicking in the head?

Morris: The kicking in the head, yes. But if the guy who was on the ball had previously punched him, then maybe a kick in the head would be justified, I'm not sure, certainly a kick in the kidneys. . So if it was retaliating, if it was in the cause of contesting for the ball or whatever, then that that kind of violence would be not just condoned, they would say "Good on you, he was getting a bit uppity."

Morris' revelation of the unwritten rules of violence, concerns with physical dominance and maintaining authority resonates with Foucault's observation that strategic relations within S\&M practices are fluid and consensual boundaries exist around the infliction of pain.

Foucault (1997b) further suggested that S\&M enthusiasts enjoy "inventing new possibilities of pleasure with strange parts of their body.... it's a ... creative enterprise, which has as one of its main features . . . the desexualization of pleasure" (p. 165). In a similar manner, the body positions and binding techniques within rugby scrums and lineouts are well known for their idiosyncratic intimacies. Although it is possible that some rugby players might gain a degree of sexual pleasure through the close body contact of rugby, my interviewees forthrightly rejected such an idea. Morris, nevertheless, reported that the close physical connections 
between rugby bodies was a good experience: "I came from a family that was very Victorian about touching one another and I think there's something good about rugby that legitimates male touching and I don't think that's a stereotype." Further, although rugby can be viewed as an entrenched aspect of New Zealand society and a normalizing mechanism for masculinities, it can similarly be viewed as an iconoclastic practice. $\mathrm{Ru}^{\mathrm{g}}$ by males, as an example, routinely shower together and drape arms over shoulders in various states of undress. Similarly, the acts of rugby aggression on the field, such as the tackle, transgress the boundaries of morality and $\mathrm{l}^{\mathrm{g}}$ ality when performed off the field. Rugby, like S\&M, can be understood as a taboo-breaking practice associated with transparent games of power connected with the excitement induced from the fear of pain and the ability to dominate. Rugby, as such, can be understood as a consensual but desexualized form of S\&M.

\section{S\&M as a Heuristic Device for Understanding Rugby}

My strategy for defamiliarizing rugby pleasures by positioning them as akin to $\mathrm{S} \& \mathrm{M}$ can also provide a heuristic framework for comprehending the broader rugby culture. Competitive rugby players, for example, do not typically hate the enemy but respect the opposition for being willing to engage in the pain, fear, and excitement of rugby. This clarifies why rugby players might attempt to batter the opposition into submission but routinely celebrate their bodily endeavors jointly in after-match functions. Further, despite sport truisms concerning health and character building abilities, participation in rugby can be understood as having little to do with the production of healthy bodies of good character. In contrast, it can be assumed that rugby players seek pleasure through physical confrontation and such risky pleasures align with rugby's well referenced connections with excessive alcohol consumption and dubious "taboo breaking" off-field activities (e.g., Schacht, 1996; Sheard \& Dunning, 1973; Wheatley, 1994).

The analogous view of rugby as a S\&M practice aids understanding for why rugby stadiums can be affectionately referred to as the "House of Pain" (Carisbrook in New Zealand); why professional teams have names like the Crusaders and Hurricanes; why wheelchair rugby is known as murderball; why rugby players have nicknames like the "Chainsaw" (Brendan Laney), "Bumface" (Will Carling), and "Le pit bull" (Brian Moore); why rugby fans might wear T-shirt with slogans stating "Give blood play rugby," "Happiness is a good ruck," and "Always kick ahead-any head"; and why a "billboard campaign for the Otago Highlanders displayed Celtic Warriors (a la Braveheart) with the slogan, "you surround them, and we'll put them to the sword" (Jackson \& McKenzie, 2007, p. 437).

Lastly, an understanding of rugby, via the S\&M lens, acts to position fans of rugby as voyeurs of pain and pleasure. This recognition offers explanation for why the most violent sporting actions tend to be shown in the media in multiple replays, including slow motion close-ups that are "narrated in ceremonial detail" (Trujillo, 1995, p. 411). 


\section{Conclusion}

I have argued that sport pleasures are important to examine because they can he understood as productive forces in the constitution of desiring sport subjects and the contemporary shape and social significance of sport. Moreover, sport pleasures deserve critical analysis as they are linked to broader structures of inequality and, within rugby, the production of injured and dangerous bodies. To examine the social significance of pleasure I conducted interviews with seven adult rugby players and analyzed how the workings of discourse and power constituted desiring rugby subjects, how these subjects negotiated experiences of pleasure, and how the implementation of technologies of dominance and self acted simultaneously in the production of rugby pleasures.

Results illustrated that the pleasures of rugby violence transported the interviewees to an edge (Lyng, 1990) that necessitated their negotiation of the blurred boundaries between pleasure and pain, confidence and fear, wellbeing and injury and, at the extreme, consciousness, and unconsciousness. The intoxicating mix shaped the players' subjectivities, desire to play and enhanced feelings of social connectedness. This edgework demanded great skill, concentration and proved addictive to some.

Given the known difficulties in explaining the joy of play and sublime experiences (see Huizinga, 1970; Lyotard, 1994) I have not provided a definitive account of the multiple rugby pleasures. Schwandt (19961 similarly reflected, "One of the principal lessons of postfoundational epistemology is that we must learn to live with uncertainty, with the absence of final vindications, without the hope of solutions in the form of epistemological guarantees" (p. 59). Gergen (1990), nevertheless, argued that the prime purpose of a postmodern researcher is not to tell it like it is but the challenge is to tell it as it may become. Inspired by Gergen, and in recognition that I found the bloody and injurious pleasures of rugby bizarre, I drew on a strategy to defamiliarize rugby pleasures: to make them strange and disrupt habitual and uncritical acceptance of rugby. I argued that rugby, like S\&M, could be understood as a taboo-breaking game associated with transparent relations of power connected with the excitement induced from physical domination and the fear of pain, and with the related satisfaction associated with the constitution of emotional solidarity. This defamiliarization strategy provided an alternative framework for understanding the broader culture of the sport as associated with the well-documented off-field practices linked with heavy-drinking, violence, sexism, public nudity and enjoyment of crude language and songs (e.g., Chase, 1006: Jackson \& McKenzie, 2007; Schacht, 1996: Sheard \& Dunning, 1973; Wheatley, 1994). Examination of rugby via this heuristic device, accordingly. lends support to the suggestion that pleasure is organized and used in a contentious manner in combat sport, while also disrupting the romanticized (and sexist) discourse that proclaims participation in rugby turns boys into men of good character. 


\section{Notes}

1. The multiple and divergent definitions of pleasure reflect debate associated with how to theorize, examine and understand emotions. Some sociologists, for example, highlight that emotions have a biological and evolutionary component or "deep sociality" (e.g., Goleman, 1995; Turner, 2000; Wentworth \& Yardley, 1994). These sociologists argue that extreme social constructionist interpretations of emotion, neglect the importance of the physiological body and by default promote dualistic thinking, as the focus on the social encourages an understanding of a mind-body separation (Maguire, Jarvie, Mansfield, \& Bradley, 2002). Dunning (1986), accordingly, argued the need to study human beings "in the round" (p. 15) and to develop a "multidisciplinary-a sociological, psychological, and physiological-theory of emotions" (p. 16). The majority of social constructionists, however, do not doubt the social significance of biological dimensions. Social constructionist examinations of sporting pain, for example, acknowledge that this physiological response to injury engenders emotions that athletes use to negotiate continued participation (Curry, 1993; Pringle \& Markula, 2005; Young, White, \& McTeer, 1994). These social constructionists emphasize that biological dimensions are interpreted differently by individuals in relation to their social contexts, interactions, and unique life histories. In this manner, they contend that emotions are socially constructed and culturally patterned (Denzin, 1984).

2. Rather than representing Foucault's thought-provoking ideas on the identification of discourses or the workings of power, I suggest that the following papers and hooks concerned with sport are useful for those unfamiliar with his work: Andrews, 2000; Markula \& Pringle, 2006; Rail \& Harvey, 1995; Shogan, 1999; Smith Maguire, 2002.

\section{Acknowledgments}

I thank Doug Booth, Toni Bruce, Mike Brown, Holly Thorpe, and the two anonymous reviewers for providing insightful feedback on earlier drafts of this article. Special thanks to Annelies Knoppers for her efficient and perceptive editing skills.

\section{References}

Andrews, D. (2000). Posting up: French post-structuralism and the critical analysis of contemporary sporting cultures. In J. Coakley \& E. Dunning (Eds.), Handbook of sports studies (pp. 106-137). London: Sage.

Andrews, D.A., \& Howell, J. (1993). Transforming into a tradition: rugby and the making ofm imperial Wales, 1890-1914. In A. Ingham \& J. Loy (Eds.), Sport in social development: tradition, transition and transformation (pp. 77-96). Champaign, IL: Human Kinetics.

Bale, J. (2006). The place of pain in running. In S. Loland, B. Skirstad, \& I. Waddington (Eds.), Pain and injury in sport: Social and ethical analysis (pp. 65-75). London: Routledge.

Barcan, R. (2002). Problems without solutions: Teaching theory and the politics of hope. Continuum. Journal of Media and Cultural Studies, 16(3), 343-356.

Barthes, R. (1990). The pleasure of the text. Oxford: Blackwell.

Bell, G., Blythe, M., \& Sengers, P. (2005). Making by making strange: Defamiliarization and the design of domestic technologies. ACM Transactions on Computer-Human Interaction, 12(2), 149-173.

Berezin, M. (2002). Secure states: Towards a political sociology of emotion. In J. Barbalet (Ed.), Emotions and sociology (pp. 33-52). Oxford: Blackwell. 
Booth, D. (2008). (Re)reading The Surfers' Bible: The affects of Tracks. Continuum. Journal of Media \& Cultural Studies, 22(1), 17-35.

Booth, D., \& Thorpe, H. (Eds.). (2007). Berkshire encyclopedia of extreme sports. Great Barrington, MA: Berkshire Publishing.

Bourdieu, (1980). The aristocracy of culture. Media Culture \& Societ ${ }^{y}, 2(3), 225-254$.

Bourdieu, P. (1986). Distinction: A social critique (f the judgement of taste. Cambridge: Harvard University Press.

Carle, A., \& Nauright, J. (1999). Crossing the line: Women playing rugby union. In 'L Chandler \& J. Nauright (Eds.), Making the rugby world: Race, gender; commerce (pp 128-148). London: Frank Cass \& Co.

Celsi, R., Rose, R., \& Leigh, T. (1993). An exploration of high-risk leisure consumption through skydiving. The Journal of Consumer Research, 20(1), 1-23.

Chase, L. (2006). (Un)disciplined bodies: A Foucauldian analysis of women's rugby. Sociology of Sport Journal, 23, 229-247.

Chu, M., Leberman, S., Howe, B., \& Bachor, D. (2003). The Black Ferns: The experiences of New Zealand's elite women rugby players. Journal of Sport Behavior, 26(2), $109-120$.

Collins, C. (2007). Studying sport in society. In C. Collins \& S. Jackson (Eds.), Sport in Aotearoa/New Zealand society (pp. 2-22). Melbourne: Thomson.

Connell, R.W. (1983). Which way is up? Essays on sex, class and culture, Sydney: Allen \& Unwin.

Csikszentmihalyi, M. (1997). Activity, experience, and personal growth. In J. Curtis \& S. Russell (Eds.), Physical activity in human e. ${ }^{y}$ perience:Intenlisciplinary perspectives (pp. 59-88). Champaign, 11: Human Kinetics.

Curry, T.J. (1993). A little pain never hurt anyone: Athletic career socialization and the normalization of sports injury. Symbolic Interaction, 16(3), 273-290.

Delcuze, G., \& Guattari, F. (1984). Anti-Oedipus: Capitalism and schizophrenia. London: The Athelon Press.

Denzin, N. (1984). On understanding emotion. Washington: Jossey-Bass.

Denzin, N., \& Lincoln, Y. (2005). Preface. In N. Denzin \& Y. Lincoln (Eds.), The Sage handbook of qualitative research (3rd ed., pp. ix-xis). Thousand Oaks, CA: Sage. Donnelly, P., \& Young, K.M. (1985). Reproduction and transformation of cultural forms in sport: A contextual analysis of rugby. International Review for the Sociology 4Sport, 20(1-2), 19-38

Duncan, M.C., \& Brummett, B. (1989). Types and sources of spectating pleasure in televised sports. Sociology of Sport Journal, 6, 195-211.

Dunning, E. (1986). Preface. In N. Elias \& E. Dunning (Eds.), Quest pr excitement: Sport and leisure in the civilizing process (pp. 1-18). Oxford: Basil Blackwell Ltd. Dunning, E. (1999). Sport matters: Sociological studies of sport, violence, and civilisation. London: Routledge.

Elias, N. (1986). Introduction. In N. Elias \& E. Dunning (Eds.), Quest for excitement: Sport and leisure in the civilizing process (pp. 19-62). Oxford: Basil Blackwell Ltd.

Elias, N., \& Dunning, E. (1986). Quest for excitement: Sport and leisure in the civilizing process. Oxford: Basil Blackwell Ltd.

Evers, C. (2006). How to surf. Journal of Sport and Social Issues, 30(3), 229-243. Falcons,

M. (2007). The decolonizing national imaginary: Promotional media constructions during the 2005 Lions tour of Aotearoa New Zealand. Journal of Sport and Social Issues, 31, 374-393.

Featherstone, M. (1982). The body in consumer culture. Theory, Culture \& Society, 1(2), 18-33.

Featherstone, M. (1991). Consumer culture, postmodernism, and global disorder. In R. Robertson \& W. Garrett (Eds.), Religion and global order (pp. 133-159). New York, NY: Paragon House. 
Finn. 0. (1994). Football violence: A societal psychological perspective. In R. Giulianotti, N. Bonne $^{y}$, \& M. Hepworth (Eds.). Football violence and social identity (pp. 90-127). London: Routledge.

Fiske, J. (1991). Understanding Popular Culture. New York: Routledge.

Foucault, M. (1977). Discipline and punish: The birth of the prison. London: Penguin Books. Foucault, M. (1978). The history of sexuality: Vol. I. An introduction. New York, NY: Random House. (Original work published 1976)

Foucault, M. (1980). Two lectures. In C. Gordon (Ed.), Power/knowledge: Selected interviews and other writings 1972-1977 (pp. 78-108). Harlow, England: Harvester.

Foucault, M. (1985). The use of pleasure: The history of sexuality (Vol. 2). London: Penguin Books.

Foucault, M. (1986). The care of the self' History of sexuality (Vol. 3). New York: Pantheon.

Foucault, M. (1987). The ethic of care for the self as a practice of freedom: An interview with Michel Foucault on January 20,1984. In J. Bernauer \& D. Rasmussen (Eds.), The final Foucault (pp. 1-20). Cambridge, MA: The MIT Press.

Foucault, M. (1988a). Technologies of the self. In L.H. Martin, H. Gutman, \& P.H. Hutton (Eds.), Technologies of the self A seminar with Michel Foucault (pp. 16-49). Amherst: University of Massachusetts Press.

Foucault, M. (1988h). The concern for truth. In L. Kritzman (Ed.), Politics, philosophy, culture (pp. 255-267). New York: Routledge.

Foucault, M. (1997a). Preface to the history of sexuality, Volume Two. In P. Rabinow (Ed.), Michel Foucault: Ethics, subjectivit ${ }^{y}$ and truth, volume one (pp. 199-205). London: Penguin Books.

Foucault, M. (1997b). Sex, power, and the politics of identity. In P. Rabinow (Ed.), Michel Foucault: Ethics, subjectivity and truth, volume one (pp. 163-173). London: Penguin Books.

Fougere, G. (1989). Sport, culture, and identity: The case of rugby football. In D. Novitz \& Willmont (Eds.), Culture and identity in New Zealand (pp. 110-122). Wellington: GP Books.

Frankl, V. (1992). Man's search for pleasure: An introduction to logotherapy. Boston, MA: Beacon Press.

Gard, M., \& Meyenn, R. (2000). Boys, bodies, pleasure and pain: Interrogating contact sport in schools. Sport Education and Societ ${ }^{y}, 5(1), 19-34$

Gergen, K. (1990). Toward a postmodern psychology. The Humanistic Psychologist, 18, 23-34.

Coleman, D. (1994). Emotional intelligence: Why it can matter more than IQ. New York, NY: Bantam Books.

Grainger, A. (2006). From immigrant to overstayer: Samoan identity, rugby, and cultural politics of race and nation in Aotearoa/New Zealand. Journal of Sport and Social Issues, 30(1), 45-61.

Gruneau, R. (1993). The critique of sport in modernity: Theorising power, culture, and the politics of the body. In E. Dunning, J. Maguire, \& R. Pearton (Eds.), The sports process: A comparative and developmental approach (pp. 85-109). Champaign, IL: Human Kinetics.

Hochschild, A. (19831. The managed heart: Commercialization of human feeling. Berkeley: University of California Press.

Huizinga, J. (1970). Homo Ludens: A study of the play element in culture. London: Rout-led ${ }^{\mathrm{g}} \mathrm{e} \&$ Kegan Paul.

Izard, C., Kagan, J., \& Zajonc, R. (Eds.). (1984). Emotions, cognition, and behavior. Cambridge: Cambridge University Press.

Jackson, S., \& Hokowhitu, B. (2002). Sport, tribes, and technology: The New Zealand All Blacks haka and the politics of identity. Journal of Sport and Social Issues, 26, 125-139. 
Jackson, S., \& McKenzie, A. (2007). Violence and sport in Aotearoit/New Zealand. In C. Collins \& S. Jackson (Eds.), Sport in Aotearoa/New Zealand (pp. 423-442). Melbourne: Thomson.

Kaomea, J. (2003). Reading erasures and making the familiar strange: Defamiliarizing methods for research in formerly colonized and historically oppressed communities. Educational Researcher, 32(2), 14-25.

Le Breton, D. (2000). Playing symbolically with death in extreme sports. Bod $(.4:$ Society, $6(1), 1-11$.

Light, R. (2007). Re-examining hegemonic masculinity in high school rugby: The body, compliance, and resistance. Quest, 59,323-338.

Lyng, S. (1990). Edgework: A social psycholo ${ }^{g}$ ical analysis of voluntary risk taking. American Journal of Sociology. 95(4), 851-886. Lyng. S. (2005). Edgework and the risk-takin ${ }^{g}$ experience. In S. Lyng (Ed.), Edgework: The sociology of risk taking (pp. 3-14). New York. NY: Taylor \& Francis.

Lyotard, J. (1994). Lessons on the analytic of the sublime (Trans. Elizabeth Rottenberg). Palo Alto, CA: Stanford Universit ${ }^{\mathrm{y}}$ Press.

MacLean, M. (1999). Of warriors and blokes: The problem of Maori rugby for pakeha masculinity in New Zealand. In T. Chandler \& J. Nauright (Eds.), Making the rugby world: Race, gender and commerce (pp. 1-26). London: E Cass.

MacLean, M. (2003). Making Strange the Country and Making Strange the Countryside: Spatialized Clashes in the Affective Economies of Aotearoa/New Zealand during the 1981 Sprin $^{\mathrm{g}}$ bok Rugby Tour. In J. Bale \& M. Cronin (Eds.),,5port and postcolonialism (pp. 57-72). Oxford: Berg.

Maguire, J. (1992). Towards a sociological theory of sport and the emotions: A processsociological perspective. In E. Dunning \& C. Rojek (Eds.), Sport and leisure in the civilising process: Critique and counter-critique (pp. 96-120). London: Macmillan. Maguire

J., Jarvie, G., Mansfield, L., \& Bradley, J. (2002). Sport IThrlds: A sociological perspective. Champaign, IL: Human Kinetics.

Markula, P. (2003). The technologies of the self: Sport, feminism, and Foucault. Sociology of Sport Journal, 20, 87-107.

Markula, P., \& Pringle, R. (2006). Foucault, sport and exercise: power; knowledge and transforming the self. London: Routledge.

McNamee, M. (Ed.). (2007). Philosophy, risk and adventure sports. Oxon: Routledge. Messner, M.A. (1990). When bodies are weapons: Masculinity and violence in sport, International Review for the Sociology of Sport, 25, 203-219.

Moller, V. (2007). Walking the edge. In M. McNamee (Ed.), Philosophy, risk and adventure sports (pp. 186-197). Oxon: Routledge.

Nauright, J., \& Chandler, T. (Eds.). (1996). Making men: Rugby and masculine identity, London: Frank Cass \& Co.

Olivier, S. (2006). Moral dilemmas of participation in dangerous leisure activities. Leisure Studies, 25(1), 95-109.

Price, M., \& Parker, A. (2003). Sport, sexuality, and the gender order: Amateur rugby union, gay men, and social exclusion. Sociology of Sport Journal. 20, 108-126.

Pringle, R. (2003). Doing the damage'? An examination of masculinities and men's rugby experiences of pain, fear and pleasure. Unpublished doctoral dissertation, University of Waikato, Hamilton, New Zealand.

Pringle, R., \& Markula, P. (2005). No pain is sane after all: A Foucauldian analysis of masculinities and men's rugby experiences. Sociology of Sport Journal, 22(4), 472-497.

Pronger, B. (1999). Outta my endzone: Sport and the territorial anus. Journal of Sport and Social Issues, 23(4), 373-389.

Rail, G., \& Harvey, J. (1995). Body at work: Michel Foucault and the sociology of sport. Sociology of Sport Journal, 12, 164-179. 
Ritchie, J. (1981). Boys will be boys: New Zealanders' approval of violence. In the proceedings: Women 's Studies Association Conference (pp. 129-140), Wellington.

Rojek, C. (1985). Capitalism and leisure themy. London: Tavistock.

Schacht, S. (1996). Misogyny on and off the "pitch": The gendered world of male rugby players. Gender \& Society, 10(5), 550-565.

Schwandt, T.A. (1996). Farewell to criteriology. Qualitative Inquiry, 2(1), 58-72.

Sheard, K., \& Dunning, E. (1973). The rugby football club as a type of male preserve. International Review of Sport Sociology, 5(3), 5-24.

Shilling, C. (2002). The two traditions in the sociology of emotions. In J. Barbalet (Ed.), Emotions and Sociology (pp. 10-32). Oxford: Blackwell.

Shogan, D. (1999). The making of high performance athletes: Discipline, diversity; and ethics. Toronto: University of Toronto Press.

Smith Maguire, J. (2002). Michel Foucault: sport, power, technologies and governmentality. In J. Maguire \& K. Young (Eds.), Theory, sport and society. London: Elsevier. Smith Maguire, J. (2008). Leisure and the obligation of self-work: An examination of the fitness field. Leisure Studies, 27(1), 59-75.

Sparkes, A.C., \& Smith, B. (2002). Sport, spinal cord injury, embodied masculinities, and the dilemmas of narrative identity. Men and Masculinities, 4(3), 258-285.

Star, L. (1992). Undying love, resisting pleasures: Women watch telerugby. In R. Du Piessis, P. Bunkle, K. Irwin, A. Laurie, \& S. Middleton (Eds.), Feminist voices: Women's studies texts fin-Aotearoa/New Zealand (pp. 124-140). Auckland: Oxford University Press.

Stranger, M. (1999). The aesthetics of risk: A study of surfing. International Review for the Sociology of Sport, 34(3), 265-276.

Sydnor, S., \& Rinehart, R. (Eds.). (2003). To the extreme: Alternative sports inside and out. Albany, NY: State University of New York Press.

Tiger, L. (1992). The pursuit of pleasure. Boston, MA: Little, Brown and Co.

Trujillo, N. (1995). Machines, missiles, and men: Images of the male body on ABC's Monday Night Football. Sociology of Sport Journal, 12, 403-423.

Tuck, J. (2003). The men in white: Reflections on rugby union, the media and Englishness. International Review for the Sociology of Sport, 38(2), 177-199.

Turner, J. (2000). On the origins of human emotions: A sociological inquiry into the evolution of human affect. Stanford, CA: Stanford University Press.

Turner, J., \& Stets, J. (2005). The sociology of emotions. Cambridge: Cambridge University Press.

Wentworth, W., \& Yardley, D. (1994). Deep sociality: A bioevolutionary perspective on the sociology of human emotions. In D. Franks, W. Wentworth, \& J. Ryan (Eds.), Social perspectives on emotion (pp. 21-55). Greenwich, CT: JAI Press.

Wheatley, E.E. (1994). Subcultural subversions: Comparing discourses on sexuality in men's and women's rugby songs. In S. Birrell \& C. Cole (Eds.), Women, sport, and culture (pp. 193-211). Champaign, IL: Human Kinetics.

White, P.G., \& Vagi, A.B. (1990). Rugby in the 19th-century British boarding-school system: A feminist psychoanalytic perspective. In M.A. Messner \& D.E. Sabo (Eds.), Sport, men, and the gender order: Critical feminist perspectives (pp. 67-78). Champaign, IL: Human Kinetics.

Wright, J., \& Clarke, G. (1999). Sport, the media and the construction of compulsory heterosexuality: A case study of women's rugby union. International Review for the Sociology of Sport, 34(3), 227-243.

Young, K., \& White, P. (1995). Sport, physical danger, and injury: The experiences of elite women athletes. Journal of Sport and Social Issues, 19(1), 45-61.

Young, K., White, P., \& McTeer, W. (1994). Body talk: Male athletes reflect on sport, injury, and pain. Sociology of Sport Journal, 11, 175-194. 